\title{
The Alienation of Social Sciences from "The Social": The Experience of Sociology Education at Kurdish Universities (KUs), Kurdistan Region of Iraq
}

\author{
Hewa H. Khedir1,2, Sangar Y. Salih ${ }^{2}$ \\ ${ }^{1}$ Centre for Religion, Reconciliation and Peace, University of Winchester, Winchester, UK \\ ${ }^{2}$ Salahaddain University, Erbil, Iraq \\ Email: sangar.salih@su.edu.krd
}

How to cite this paper: Khedir, H. H., \& Salih, S. Y. (2020). The Alienation of Social Sciences from "The Social": The Experience of Sociology Education at Kurdish Universities (KUs), Kurdistan Region of Iraq. Advances in Applied Sociology, 10, 23-40. https://doi.org/10.4236/aasoci.2020.102003

Received: December 29, 2019

Accepted: February 21, 2020

Published: February 24, 2020

Copyright $\odot 2020$ by author(s) and Scientific Research Publishing Inc. This work is licensed under the Creative Commons Attribution International License (CC BY 4.0).

http://creativecommons.org/licenses/by/4.0/

\section{Abstract}

This paper examines the extent to which sociology in Kurdish Universities (KUs), Kurdistan Region of Iraq (KRI) is connected to the reality of Kurdish society. In this regard, the reflections of Kurdish "the social" in teaching and sociological research have been studied. Methodologically, the research employed qualitative research techniques by conducting (16) semi-structured interviews with professors and three focus-group interviews with students from sociology departments at three prominent universities in KRI. Findings show that the alienation of sociology as a discipline has apparent manifestations in teaching sociology and to a lesser extent in sociological research. Sociology curricula in the three departments have not effectively made Kurdish society, culture, politics the subject matter for sociology education. Writings about Kurdish society, though not plentiful in Kurdish language, have scarcely if ever, been used in teaching. Assignments remain primarily traditional (paper-based exams) and the field work is not systematically oriented and supervised. As to sociological research in KUs, in spite of the connection of those projects to a wide array of social issues in Kurdistan, challenges remain with the usage of research in teaching and lack of methodological diversity in most of the projects.

\section{Keywords}

Sociology, Kurdish Sociology, Sociological Study, Pedagogy, Sociology Curricula 


\section{Introduction}

Social sciences in general and, sociology specifically being one of them, are new to Kurdish Academia. The foundation of the first department of sociology dates back to 1976 when the department was first opened at the University of Sulaimani ${ }^{1}$. Thus, institutionally, sociology arrives in Kurdish academia after nearly two decades of its introduction in Baghdad University (Al Hashimi, 2013). The department began its postgraduate programs in 1994 (Rasul, 2018). University of Salahaddin remained the only university in the region providing a home for the sociology department until mid of ninetieth of the last century. The horizontal expansion of universities in KRI in the decades ensuing the establishment of the Kurdistan Regional Government 1992 was accompanied by mounting interest in social sciences. Universities, public and private, began to establish departments of sociology and other social sciences. At the present, there are five departments of sociology at Kurdish Universities (KUs) ${ }^{2}$. In addition, many other KUs are offering sociology related courses in various schools such as political sciences, business and administrative sciences and law.

After four decades from its embryonic conception, sociology still has not exceeded its initial stages. Kurdish sociologists still have difficulties to apply sociological theories and to employ scientific methods in their studies (Hakim \& Muhammad, 2017). In spite of a numerical growth of sociology programs in KUs and a rapid increase in the number of students that enroll in sociology programs $^{3}$, it seems that sociological community in KUs failed to transform sociology to an indigenous specific scientific discipline. As it will be presented later, sociology in Kurdistan has been heavily influenced by its western roots in two important ways: Sociology at Salahaddin and Sulaimani was shaped by Western model indirectly by following the sociology model of University of Baghdad which itself once had been imported by Iraqi returnee sociologists in 1950s. One the other hand, the younger department of sociology at Soran University is directly influenced by the Western model of sociology by a group of Kurdish academics who returned from Western countries after 2003.

On reviewing the available literature, it becomes apparent that there is a paucity of publications about sociology in Kurdistan (Hakim, 2017; Hakim \& Muhammad, 2017; Rasul, 2018). This paper will be the first, to the best of our knowledge, systematic sociological study of sociology of sociology in Kurdistan. The paper will transcend the institutional and technical aspects of sociology education to cover variety of social and cultural influences on teaching and researching in sociology. In this paper, we would argue that sociology in KUs alie${ }^{1}$ In 1981, the University of Sulaimani was transferred to Erbil city and was named University of Salahaddin. After the foundation of Kurdistan Region Government, the University of Sulaimani was reopened in 1992 .

${ }^{2}$ The universities which have departments of sociology are University of Salahaddin-Hewler, University of Sulaimani, Soran University, University of Duhok and Lebanese French University. The department of sociology at Koya University was established in 2008 then closed in 2014.

${ }^{3}$ Since 1979 (2824) undergraduate students have graduated from the department of sociology at Salahaddin university only. 
nated from "the social": it has failed to explore its original non-Western intellectual roots; it has been unable to examine social, political and cultural context of Iraqi and Kurdish society; it has been ineffective in generating original knowledge about its own context; it has been unsuccessful in developing a tailor-made pedagogy for teaching sociology.

The paper, therefore, addresses a wide array of issues from conceptualization of sociology to institutionalization of sociology and sociology as a research endeavor in KUs.

\subsection{Literature}

In the family of social sciences, Sociology is comparatively a new entrant. As a scientific field, sociology emerged in the context of modernization (Tayefi, 2010). Due to its direct tackling with social change, social problems, social relationships and social interactions (the reality of people's life) sociology became an attractive field of education not only in the West (the place of its origin), but also in non-Western countries including Iraq.

Sociology was first introduced in the Middle East by Egyptian sociologists in the early $20^{\text {th }}$ century. The founding fathers of sociology in Egypt were PhDs holders who received their sociology trainings in France. Therefore, most of them were significantly influenced by the Durkhiemian School of sociology (Bagader, 1997). Not surprisingly, emerging sociology early in Egypt has led Egyptians to be considered as the forerunner sociologists in Middle East. In Iraq, the influence of Egyptian sociologists was evident in textbooks, curricula, and even sociological studies (Ibrahim, 1997; Bagader, 1997).

The history of sociology in Iraq can be traced to 1920s when sociology was among the courses offered at the university level. Whilst sociology courses were not delivered by specialized sociologists, it is still considered as a significant juncture for the introduction of sociology in the country (Qazzaz, 1980; Al Hashimi, 2013). Later, Iraqi students namely Ali Al-Wardi (1913-1995), Abdul-Jalil Al-Tahir (1917-1971) and Hatem al-Kaabi (1917-1979) obtained their PhDs in sociology from U.S universities and returned home in the early 1950s. As the first generation of Iraqi sociologists, particularly Ali-Al-Wardi championed the development of sociology as an independent academic discipline. Their attempts resulted in the establishment of the first department of sociology at the University of Baghdad in 1954 (Abdul-Hussain, 2014). Since then, ten similar departments have been established across the country (including sociology departments at KUs). Thousands of students have received sociological training, hundreds have received higher degrees both inside the country and abroad and a number of books have been written about sociological issues (Al Hashimi, 2013). However, apart from Ali' Wardi's writings, Iraqi sociology has not been able to provide deeper and more sophisticated analysis for Iraqi culture and society. In consequence, this has prevented students from developing a critical understanding of Iraqi society and culture (Bagader, 1997; Ibrahim, 1997; Abdul-Hussain, 2014). 
The state of sociology in the Kurdistan Region does not seem to be much different from the rest of Iraq. Kurdish sociology has enormously been influenced by Iraqi sociology. This could be well related to the fact that non-Kurdish sociologists (Arab sociologists from other part of the country) established and then ran the first department of sociology at the University of Salahaddin Hewler almost for two decades. The first generation of Kurdish sociologists also studied and worked under the supervision of the Iraqi sociologists back in 80s and 90s in the last century. This generation has played a significant role to educate other Kurdish sociologists who studied and graduated from the departments of sociology at different Kurdish universities in the region including universities of Salahaddin, Sulaimani, Soran and Koya.

After 2003, another group of Kurdish sociologists emerged. These are Kurdish academics who had received master and doctorate degrees from leading international universities in North America, Europe, and neighboring countries. Majority of students had been granted Human Capacity Development program (HCDP) scholarships by the Kurdistan Regional Government. These sociologists have returned home to work not only at Kurdish universities, but also in other governmental institutions.

Noteworthy to mention that there are a few researches that shed some light on Kurdish sociology. Izaddin Rasul (2018) provides basic details for 296 thesis and dissertations in Bibliography of Sociological Researches. Izaddin Rasul evidences (see Table 1), the majority of the Kurdish sociologists obtained their degrees from the Iraqi and Kurdish universities, of which 121 are obtained only from the University of Salahaddin. Thirty seven degrees are received from other universities in the Arab countries and 49 from other foreign countries. More specifically, 24 degrees are awarded by Egyptian universities and 19 by the UK universities. This indicates that Kurdish sociologists who studied abroad are mostly trained in Egypt and UK.

Rasul's work (Ibid) reveals that sociological dissertations suffer from the problem of duplication of research projects across sociology departments. This may be well related to the lack of knowledge dissemination tools in the region, which is not a problem only in sociology but also in all disciplines (Atrushi \& Woodfield, 2018). Epistemologically and methodologically, research has shown that sociology in Kurdistan has overwhelmingly shaped by positivism and the overarching methodology is of quantitative approach. Furthermore, in the context of quantitative approach, vast majority of research projects employed survey techniques, albeit in many ways unsuccessfully (Hakim \& Muhammad, 2017). In

Table 1. MA/PhD sociology degrees breakdown by Countries.

\begin{tabular}{cccc}
\hline Where the degree is awarded & MA & PhD & Total \\
\hline Iraq & 166 & 44 & 210 \\
Arab countries & 34 & 3 & 37 \\
European \& Western Countries & 42 & 7 & 49 \\
Total & 242 & 54 & 296 \\
\hline
\end{tabular}


another work, Hakim (2017) criticizes sampling techniques in many research projects on the grounds of their incompatibility with research questions and the inappropriateness of sampling selection procedures.

Aforementioned attempts focused solely on sociological researches while other dimensions of this scholarship in the region obviously remain unstudied. In this regard, sociology curriculum (type and content of the courses) as well as how these courses are delivered (pedagogy) in sociology departments have so far not been investigated. Contrary to that, in Western context there have been enormous experimental studies about teaching, learning and pedagogically issues in sociology. For instance, Teaching Sociology as an academic journal has published articles, notes, and reviews since 1973 intended to provide theoretical and practical information useful for professionals teaching sociology courses (American sociological Association, 2018). Among others, critical pedagogy has been identified as a powerful strategy in teaching sociology literature (Braa \& Callero, 2006; Kaufman, 2002). This is simply because it does not only tell us how to teach and learn-much less what to teach and learn; rather, it also implores us to use our teaching and learning to effect positive social change (Fobes \& Kaufman, 2008). This comprehensive analysis is deeply rooted in the work of the Brazilian educator, Paulo Freire (1970). In his seminal text "the pedagogy of the oppressed" Freire clearly explained two models of education; banking model of education and problem-posing education. The former considers students as containers into which teachers must put knowledge while the latter emphasizes that knowledge is not deposited from the teacher to student but is instead formulated through dialogue between the two. Knowledge is not only taught by the teachers but also taught to the teachers together with students. In other words, the teachers and learners jointly undertake the act of knowing. This act is a dialectical movement from action to idea and from thinking on action to a new action. Praxis, which is a combination of reflection and action helps students to gain a critical awareness of their condition to struggle for liberation. This is a pedagogical approach which is proposed by Freire to localize education and use it as a means of positive social change.

Closely related to the link between sociology and pedagogy, sociologists argue that all sociological knowledge has potential pedagogical implications. It is simply because sociology provides a great deal of information about the manifestations of racial, ethnic, gender, class, and other structural dynamics in classroom interactions. Sociology informs us of these structural dynamics. Therefore as a discipline it is considered as pedagogy (Halasz \& Kaufman, 2008).

\subsection{Data and Methods}

This research utilizes techniques of qualitative research. As data collection methods, both semi-structured and focus-group interviews were employed to generate data. More precisely, the analysis presented in this paper is based on three focus group discussions and 16 individual semi-structured interviews in sociol- 
ogy departments at three universities of Salahaddin, Soran, and Sulaimani. ${ }^{4}$ Regarding the focus-group interviews, nearly 30 students from the three departments were invited for the sessions. Professors to be interviewed were selected by using purposive sampling. Interviewees were selected based on the following criterion: 1) obtained MA or $\mathrm{PhD}$ degrees in sociology, 2) and currently serving as a faculty member of sociology department at one of the above mentioned universities. We made it certain that the sample will include professors who have received their degrees from KUs, Iraq universities and other countries' universities. Thematic Analysis was used in data analysis section (see Table 2).

\section{Data Analysis}

\subsection{Professor's Interviews}

\section{Conceptualization of sociology}

A science to study society in terms of its social structure, social organizations, social problems, social phenomena and so forth has been central to most of the definitions that interviewees provided to sociology. Nevertheless, some of the professors ${ }^{5}$ found it difficult to define sociology straightforwardly. Ambiguities about sociology's subject matter, its overlap with other social sciences and disagreements between schools of sociology explain such an ambiguity. Moreover, sociology is described to "objectively" examine a wide range of issues from individual behaviors in its relationship with social and physical worlds, to gender, ethnic conflict, social welfare, environment, political parties, elections and so on.

Sociological knowledge tends to be dynamic as it is a product of examination something "ever changing and becoming". A number of interviewees suggested that since society changes constantly, the knowledge about it changes accordingly. An interviewee from Salahaddin University stated that "it is hard to understand individual behavior...it changes and over times becomes different...and then do not forget that our behavior differs when we are by ourselves and when we are in the presence of others". This has its implications for individual behavior as it is a result of interaction with a changing environment. This uncertainty, for some interviewees, has made sociology a lively and enjoyable

Table 2. Demographic background of professors sampled in this research.

\begin{tabular}{ccccccccc}
\hline \multirow{2}{*}{ Demographics } & \multicolumn{2}{c}{ Gender } & \multicolumn{2}{c}{$\begin{array}{c}\text { Academic } \\
\text { Degree }\end{array}$} & \multicolumn{2}{c}{$\begin{array}{c}\text { Country in which } \\
\text { degree was obtained }\end{array}$} \\
\cline { 3 - 9 } & Female & Male & MA & Ph.D & Kurdistan/Iraq & Arab Countries & Europe \\
\hline \multirow{2}{*}{ Sniversities } & Salahaddin & 1 & 5 & 2 & 4 & 4 & - & 2 \\
& Sulaimani & 2 & 4 & 3 & 3 & 3 & 2 & 1 \\
\cline { 3 - 9 }$N$ & Soran & 1 & 3 & 3 & 1 & 2 & 2 & 5 \\
\hline
\end{tabular}

${ }^{4}$ The sociology departments at both Duhok and Lebanese French Universities are purposively excluded. This is solely due to the fact that the former has only one faculty member and the rest of its teaching staff are visiting lecturers coming from other sociology departments, and the latter's newness and that it only has one group of students being admitted in academic year 2017-2018.

${ }^{5}$ Throughout data analysis the word "professors" will mean professors interviewed and the word "students" indicates to students interviewed for the project. 
endeavor as it makes scientific exploration perpetual and, simultaneously, makes it challenging since it renders sociological knowledge uncertain and fragile.

Another area of agreement in the interviews focuses on the constructive role that sociology ideally should play in micro and macro levels. On the micro level, interviewees stressed that sociology can help individuals understanding their behavior and their social problems and subsequently makes them more efficient in their interactions with others. An interviewee from, Sociology/Soran University, contended that "sociology is about creating people who can see things differently... be critical and able to see many latent things that others are not able to see". Another professor said "now I am like a consultant for my family...they turn to me to discuss many family-related issues". This view, in spite of its popularity, is not shared by everyone across interviews. A young professor from University of Sulaimani stressed that "solving individual problems is not the duty of sociologists...this is something that social workers and psychologists can do...sociology is about understanding and explanation". On macro level, again, there is an overarching agreement that sociology is expected to contribute to social change and development. Findings of sociological research need to be utilized in the process of planned development. An interviewee from University of Sulaimani went beyond the conventional understanding about sociology and sociologists as neutral and objective, by stating that "sociologists need to be actively promoting change". He mentioned that many prominent sociological figures (without mentioning any names) in other parts of the world (perhaps in West) who actively engaged in social and political movements aimed at bringing about change in those contexts.

Having said that, the bitter reality for most, if not all, of the interviews, is the "marginalization" of sociology in this process. Across interviews, reference was made to lack of government and society's interest in sociology. The marginalized role of sociology, apart from the structural causes, is additionally explained by the fact that sociology has not yet touched the social reality of the Kurdish context. Many interviewees stressed that, until now, a sociology that can produce a theory about Kurdish society does not exist. Therefore, knowledge about Kurdish society, a proper methodology to examine the distinctiveness of this society, and a sociological school to offer an explanation for the dynamics of this society is missing. Nonetheless, an interviewee from University of Sulaimani recognized some positive changes that social sciences contributed to in KRI. He pointed to banning physical violence in schools as something social sciences pushed for and achieved. But still, as stated, an overall disappointment is dominant that sociology is ignored and sociologists are powerless.

Hostility, mainly on cultural or religious grounds, to sociology was raised by interviewees from the Soran University. Interviewees reported of being exposed to nearly no academic or institutional censorships. However, due to conservative nature of the community, which sometime has shaped the mindset of some academics, they find research and discussing certain issues in public enormously problematic. A professor narrated her experience requesting cooperation being 
declined by one of departments due to the subject of her research, hijab (Women's Veil). Notions such sociologists are atheists or Marxists are common in academic and non-academic environments. Stereotyping sociology in this way has made some students feel uncomfortable studying sociology. An interviewee from Soran University pointed to the extreme "cognitive dissonance" that students struggle with as a result of their most fundamental religious values and upbringing challenged by sociological explanations in sociology classes. As a consequence, according to the same interviewee, some students find it uncomfortable or regretful to study sociology. This friction has rarely, if at all, been mentioned in our interviews at universities of Salahaddin and Sulaimani.

\section{Institutional Dimensions}

\section{Curricula}

Compared to an overall agreement regarding the conceptualization of sociology, we found a relatively profound variation with respect to the content of sociology programs in the three universities. Before providing a critique of those differences, it is perhaps necessary to point to the fact that sociology departments at universities of Salahaddin and Sulaimani, up until very recently, have followed the same curricula. It was partly due to the fact that sociology at University of Sulaimani was established by few professors who had, in the past, worked at sociology department at University of Salahaddin Hewler. Thus when they established sociology at University of Sulaimani in the mid-1990s, they followed the University of Salahaddin Hewler's model and, in essence, both of them have substantially copy-and-pasted the sociology model of University of Baghdad. Sociology at Soran University flourished from entirely different seeds. It was established, as stated before, by a number of Kurdish academics who had returned from Western countries and developed a Western model of sociology in Kurdistan. They were reluctant from the very beginning to imitate other local sociology departments. As a result, one can easily detect, as it will be made clear, many sharp differences not only in terms of curricula, but in many other institutional aspects of sociology education between Salahaddin and Sulaimani universities, on the one hand, and their counterpart department at Soran University, on the other hand.

There is almost a clear distinction between the three departments in regard to sociology curricula: dissatisfaction with the curricula, especially for younger professors at University of Salahaddin, a more acceptance of the program at University of Sulaimani and a sense of proud in the program at Soran University.

In spite of recognition for the value of some courses, the curricula were described as outdated, general and disassociated from reality at University of Salahaddin Hewler. Interviewees very often criticized course as they do not keep up with the progress that has been made in the sociology education elsewhere. Courses remained the same for decades with virtually the same content. Additionally, it was suggested that the courses lack depth. An interviewee told us that "[they] have many courses with too little about each subject". This view was 
shared by many others not only at Salahaddin but also at University of Sulaimani. Equally important, is the view that courses do not reflect the Kurdish context. Interviewees were willing to concede that course contents need to introduce students to various aspects of Kurdish society, history, culture, politics, and economy. Even the single course, Kurdology, which was introduced to enable students to understand Kurdish society, is delivered in a wrong way. According to a number of interviewees, the course focuses on the history, geography, literature of Kurdistan without examining those aspects from a sociological point of view. In the same vein, a young professor from University of Sulaimani said: "[they] even failed to catch up with the neighboring countries... in Iran, because of the years of war with Iraq [1980-1988] they have Sociology of War, [as a consumer society] in Turkey they have Sociology of Consumption and Sociology of Film".

While sharing some of these concerns, professors from University of Sulaimani were more comfortable with the curricula. Apparently, it is essentially due to their ability to revise some of the program. In their response to the question, which course do you find not interesting and believe that need to be removed/replaced, some of the interviewees suggested that "[they] have already removed some unnecessary courses and replaced them with new ones". Reflecting their assessment for the societal needs, they added course on Sociology of Gender, Sociology of Globalization, Sociology of Crime, Sociology of Religion and Sociology of Culture. They simultaneously removed some other course such as, but not limited to, Sociology of Industrialization and Arabic Language.

As has already been mentioned, sociology program at Soran University is younger and follow more or less a western style of sociology education. A sense of satisfaction and proud about courses is dominant. One can observe that there is a significant emphasis on teaching social theories and research methodology. While social theories are taught as a single course in the fourth year at University of Salahaddin and University of Sulaimani, it is broken down to three different courses (Classic Social Theories, Modern Social Theories and Contemporary Social Theories) in three different years at Soran University. The same applies to research methodology as it is one course in the year two at Salahaddin and Sulaimani universities; it is taught in two years at Soran University and has been split to Quantitative Research and Qualitative Research Methodology. Professors also insisted that their program not only meet the "international standards" but also reflect the needs of Kurdish society. A reference was made to course on Colonialism, Nationalism, gender, sociology of religion and genocide as examples for such a consideration.

Having said that, a sporadic dissatisfaction from the part of younger, lower in the academic ranking, professors has been evident across interviewees in the three departments. According to rules and regulations, the mandate to decide about courses and course contents is lied in the departments' Academic Boards. This board, technically, consists of staff members who hold Ph.D. degrees or hold assistant or full professorial titles. Academics in the lower ranks lack power 
and often have no significant say in academic-related decisions. So very often, younger interviewees tended to complain that though they have ideas to take their departments forward, they are not listened to. Hence, ideas remain ideas and will not be translated to academic policies.

\section{Pedagogy}

In spite of some individual differences among professors, a variation in the way sociology is taught can be observed among the three departments. Interviewees from University of Salahaddin and University of Sulaimani commonly described their teaching style as a more of classic nature (though they did not describe it as classic) and that they mainly lecture in classroom settings. In contrast, more diverse teachings methods is reported to have been employed at Soran University as teaching involves workshops, field work and essay writings. It should be mentioned that none of the interviewees at Salahaddin and Sulaimani traced that to unfamiliarity with the modern techniques of education. They, in fact, referred to practical and logistic barriers that prevent them from utilizing other methods. There has been a significant emphasis on the size of classes (in some cases they have more than 70 students in one classroom) and lack of technological facilities. Moreover, there have been complaints about motivations and qualifications of students. A substantial number of professors stated that students are not motivated and when "they are required to present a report on something they just copy and paste from another document". Students were also criticized for their inability to think critically. The pre-university education system is believed to have made students depend on memorization not understanding. Lack of language skills seems to have exacerbated the problem as vast majority of students have no access to a second language. A professor from $\mathrm{Su}-$ laimani University argued that departments must have more control over admission process in order for them to be able to recruit more motivated students. Seemingly, the whole economic crisis coupled with students' pessimism with respect to the availability of job opportunities after graduation have further harmed the motivation and interest of students.

Teaching material is for the most part derived from non-Kurdish sources. Most of the teachers depend on Arabic and, to lesser extent, Farsi and English sources. As a consequence students are likely to have limited access to knowledge which has been produced about Kurdish society in other languages. More recently, growing scholarly interest in Kurdistan and the increase of Kurdish academics in Western countries brought about proliferation of sources about Kurdistan. However, in none of our interviewees were we told about the use of these sources in teaching.

Assessment process at Salahaddin and Sulaimani universities are greatly identical, with more flexibility at the later. Roughly $90 \%$ of the assessment is paper-based exams. Student will need to undergo two paper-based exams (30\%) throughout the academic year before they have another $60 \%$ final paper-based exam. The remaining $10 \%$ is left for students' in-class participation, reports, seminars and other activities. Individual differences, however, exist. A professor 
from University of Sulaimani stated that he will not give any paper-based exam out of the first (30\%) part of the assessment. He instead requires students to produce essays or field work reports. Some other professors uncommonly use similar assessment tools. Sociology at Soran University, while also committed to the $30-10-60 \%$ division, often encourages students to produce essays and make in-class presentations.

\section{Research}

Professors' research include broad range of issues from ethnic and community relations, to culture and environment, migration and displacement, urbanization, education, social organizations and social control, political parties, gender, sport, suicide, women and violence, genocide, well-being, social theory and many other topics. The overwhelming majority of projects have examined subject matter in the Kurdish context. Methodologically, although quantitative research (exclusively surveys-based questionnaires) tends to be common, there has recently been a tendency by younger professors to employ qualitative research techniques. In this regard, reference has been made to individual interviews, focus group interviews and observation.

Few remarks about research projects are outstanding. First and foremost, there has been a disappointment that research findings are ignored and have not been used in any way to shape policy. This, in essence, partly explains the overall pessimism of professors that sociology has failed to contribute to planning and development in Kurdistan. As a result, research has mostly remained to serve the individual academic purposes of professors. Repeatedly, interviewees pointed out to tarqia (the Arabic word for promotion) while explaining their choice to carry out research or to decide about their research topics in the first place.

Furthermore, recent diversification of research methods and the growing interest in qualitative research has not always been a smooth shift. Resistance, from the older generation, to the use of some research techniques has been reported of. A young interviewee from University of Salahaddin Hewler said: "they made fun of me when I used focus-group interviews...they said this is not a research". Another interviewee from Soran University narrated that it was not easy for him to use online questionnaire.

On the other hand, research projects lack the comparative perspective. Research project have tackled issues in the Kurdish context (mainly in the urban settings) only and have not undertaken regional or cross-country comparisons. To the best of our knowledge, there has been one Ph.D (Hakim, 2011) thesis that made use of World Value Survey data and therefore provided a comparative standpoint on the change in social value systems.

Censorship, on cultural grounds, again was raised by interviewees at Soran University. Issues related to gender and religion tend to be more problematic. An interviewee said "I am always asked why sociologists always study tough [culturally sensitive] things". This will be trickier if research findings circulated in public discussions. The same interviewee explained the harsh criticism she 
received when she presented her research findings on the motivations of hijab in the Kurdish society.

In the end, apparently, circulation of research reports takes place in extremely narrow circles. Up until very recently, Kurdish academic journals were not available online. Thus research reports were only publishable in traditional hard-copy formats and were stored in traditional library shelves. A number of interviewees stated that they are not aware of their colleagues' publications let alone publications of other sociologists in other universities.

\subsection{Focus-Group Interviews with Students}

\section{Conceptualization of Sociology}

From a Classical to a Radical/ Emancipatory Understanding of Sociology

The conceptualization of sociology, the way it is presented by students, reflects classical themes that early sociologists identified for the study domain of sociology. Students have frequently described sociology as a study of social phenomena, social problems: their causes, effects and solutions, social relationships, social institutions, culture and so forth. Nevertheless, students in the departments of sociology at Soran and Sulaimani Universities, tend to transcend this classical definition and point out to themes that constitute the core of a more radical/emancipatory version of sociology. In these two schools, students place a significant emphasis on sociology as a scientific endeavor to present a more critical understanding of culture, religion and politics. Expressions such as "there is no such a thing as sacred/ holy in sociology", "sociology studies everything from culture to religion to politics in a critical way", "our society is tribal and religious, but sociology is about democracy and creation of a modern world", "change is not allowed because of religion and politics" have been repeated often in our discussions with students.

From an epistemological viewpoint, students stress on the uncertainty of sociological knowledge and the relativeness of social world. There is an obvious recognition that cultures are different and "nothing is perfectly true" and "sociologists stay neutral and refrain from making judgments [about other culturesp'. Moreover, students focused on sociology's attention to study the influences of "society on individual" and that sociology studies "the societal aspects of everything".

\section{Sociology: Vague and Anti-social}

In spite of the fact that students were able to make reference to many positive changes that sociology brought to them on individual level (will be explored in upcoming section), there is an apparent disappointment, from the students part, that sociology is an undervalued science. Students expressed confidence that sociology can contribute constructively to social change and can help addressing social problems, yet they believed that government overlooks the important role that sociologists can play. Similarly, participants in the focus-groups contended that society itself has no clear conception of sociology, though in a few instances 
students reported that they face high expectations that as sociologists they are expected to solve individual and social problems. Students reported on the experience being encountered with questions such as "what is sociology?", "what are you going to be in the future?", "what is difference between psychology and sociology?" as examples of the vagueness/or absolute absence of any concept of sociology in their communities.

Apparently, students too, find it a struggle to introduce sociology to the broader community. In response to our question "how do you describe sociology to your family members, neighbors or friends?", they either failed to define sociology in a socially understandable language as they, for the most part, used the same technical and classical concepts of sociology textbooks or they described sociology through the lenses of psychology and social work. Some students mentioned that they would say that "sociology is there to understand individuals", or "sociology solves your family problems" or "sociology makes you understand yourself better".

Correspondently with the radical/emancipatory conception of sociology in the department of sociology at Soran University, participants in the focus groups complained about the negative reactions that the community (sometimes even scientific community) displays towards them. Sociologists are portrayed as "anti-religion" and "Marxists" and their call for gender equality and challenge they pose to many socially accepted values and norms received with resistance. A female student while narrating her application and later admission to the department of sociology at Soran University said that a cleric had told her mother that "she [the female student] should not have gone [to this department], if she hasn't yet, let her doesn't go". Students' intellectual criticism and emotional anger, especially in sociology at Soran University was openly pronounced.

\section{Students' Worldview: Deep Changes}

Although the vast majority of participants in the focus groups reported that sociology had never been their first educational preference and that, in some instances, they experience community disapproval; they express boundless satisfaction with being sociology students. Students were keen to make reference to the deep changes that took place in their worldview and in their individual value systems. Expressions like "I see things differently" and "I do not jump to make judgments about other people and cultures", "I explored myself by studying sociology", "I started to feel that I have many social responsibilities towards my society", "before I would think that many things should be taken for granted and should not be questioned" have been widely shared in our discussions. The changes on individual level extend to include deeper changes in the individual value systems. A male student from Soran University, while explaining the differences that sociology brought to his way of thinking said "before I would think that a man is a man and a woman is a woman... a woman should stay at home and should take care of household tasks and a man should do other thing outside [the home]... but now I think many things that a woman does can also be 
done by men...I personally do many things that I would not do [because they were culturally thought inappropriate for men?'. In addition, students demonstrated that they are now more in favor of cultural diversity, more optimistic about others, they feel more responsible towards environment, more self-confident and more critical about culture, social norms, religion, traditional power (at home or in broader community). This critical aspect applies strongly to participants at Soran University and to a less extent to participants at University of Sulaimani.

\section{The Institutional Dimension \\ Curriculum}

Students' subject preference reflects perfectly the extent to which subjects are linked to students' individual and/ or collective reality, satisfaction with teachers' pedagogy and the presence/ absence of egalitarian relationships with professors. Although departments of sociology at University of Salahaddin Hewler and University of Sulaimani virtually follow the same curriculum, differences between students, in terms of subject preferences, are obvious. Students at University of Salahaddin Hewler very frequently pointed to Psychology, Social Psychology, and Criminology and to a less extent to Anthropology and Sociology of Knowledge as examples for subjects they liked most. At University of Sulaimani, there has been frequent reference to Philosophy and Sociology of Education as two extremely popular subjects followed by a less reference to Political Sociology and Sociology of Culture. While in Soran University, which follows a significantly different program, popular courses include Sociology of Education, Sociology of Gender, Social Psychology, Nationalism, Imperialism and Colonialism with sporadic references to Sociological Concepts, Introduction to Sociology, Sociology of Religion and Social Policy.

In spite of differences in subject preferences across the three departments, there exists an overwhelming correspondence among students that subject preferences are shaped categorically by professors' pedagogy (which will be discussed later) and the professor-student relationships. Students at University of Sulaimani stressed heavily on the egalitarian disposition of some teachers to explain why they do like some courses other than other courses. Complains about the arrogance of some teachers and their reluctance to pay attention to students were common. A female student, while expressing her disgust about a professor, said "I would prefer cleaning the whole university to attend $(X)$ 's one hour class". The link of the course to reality also explains subject preferences (will be explained in the following section).

\section{Pedagogy}

Focus-group discussions reveal that teaching pedagogy at the two Departments of Sociology at University of Salahaddin Hewler and University of Sulaimani tend to be of a more traditional/ lecturing typology. In spite of the fact that few professors will make some use of modern technology by making PowerPoint presentations, the rest of professors do mainly follow classic/teaching style. This is almost entirely different when it comes to Sociology at Soran University. Par- 
ticipants pointed to their professors using a combination of teaching methods ranging from class/lecturing methods to use of case studies, video blogs and class workshops. Students, especially at Sociology/University of Sulaimani, complained openly about some professors' reluctance to raise questions and to intellectually engage with students. As mentioned above, none of the courses were identified as a preferred subject if students were not happy about professors' pedagogy in the first place.

\section{Link to the Context}

Assignments in the form of essays and reading materials can bridge theoretical knowledge to the reality. Essays, in the two departments of Sociology at University of Salahaddin Hewler and University of Sulaimani tend to be, for the most part, disconnected from reality and, in most of the cases, not thoroughly guided and marked. Participants reported that normally teachers allow them to select a relevant topic (from course book if there was any) to the course and write a literature-based article about it. Apparently, professors have not provided students with a comprehensive guideline about questions that need to be addressed or even to thoroughly advice students on possible references (though few teachers do). Essays, as have already been mentioned, lack connections to reality. Few participants at University of Salahaddin Hewler pointed to one assignment they had in Research Methodology and Social Statistic Courses where they were requested to engage in some data collection and conduct some preliminary data analysis. Classes and Assignments remain predominantly theoretical and the realty of Kurdish Society is left unstudied. Furthermore, essays in the two departments are not taken seriously by professors. Students at University of Sulaimani demonstrated dissatisfaction as a result of being ignored when they turned to some professors for support or when their essays marked carelessly. A Student said "teachers give marks according to name of students [not the content of the essayp. This tends to be not exactly the case in Sociology at Soran University where closer guidance is noticeable and professors have shown eagerness to support students on the assignment.

Consequently, class discussions and assignments barely cover social issues of Kurdish society. A student in Sulaimani's focus group said: "up until now we have not taken any case study or a proper example about Kurdish Society... when I asked a teacher to give us examples from the Kurdish society s/he declined my request by saying I am not going to talk about Kurdish society... it is a mess and I am afraid that if I talk about Kurdish society I may make you pessimist". Another teacher had said, quoting a student "forget Kurdish society... we cannot solve its problems". In the same vein, students stressed that their departments need to involve them in field visits and develop a placement program.

Further disconnection of Sociology from the Kurdish reality has manifested in the designation of course readings. When students were encouraged to give examples for sociological thinkers, participants find it easy to point to Ibn Khaldun, Emile Durkheim, Herbert Spenser, Karl Marx, Max Wiber, Karl Mannheim 
(in all three departments) or modern sociological thinkers such Michel Foucault or Jurgen Habermas (mainly at Soran University). Students failed to mention any Kurdish or Arab scholars (apart from Ibn Khaldun). Moreover, course readings are also, for the most part, the translated versions of some Western, Arabic and Persian sources. Examples of books, which students have recently read, are devoid of any material written by indigenous scholars or even written about Kurdish Society by non-Kurdish scholars.

\section{Conclusions}

Decades have passed since the establishment of the first department of sociology in seventies of the last century in KUs. Institutionally, sociology has not made any significant deviation from its Iraqi roots (in the case of sociology departments at University of Salahaddin Hewler and University of Sulaimani), or, recently, from its western model (in the case of sociology department at Soran University). The outcome for such a reality has been a profound failure in indigenization of sociology as a science to study Kurdish society. This study has shown that alienation of sociology from "the social" has had palpable manifestation in the teaching aspect other than in research. In the case of sociology at universities of Salahaddin and Sulaimani, in spite of slight differences, courses and course contents remained intact for ages; courses have remained introductory and subsequently have lacked depth; Kurdish society as a subject matter has been absent in the curricula; pedagogy remains of lecturing-based style; assessment process is mainly traditional exam-based; assignments cannot help students link the theory to the reality of Kurdish society; course references are chiefly Arabic, English and Persian languages written by non-Kurds and present no direct readings to Kurdish society. With respect to Sociology department at Soran University, having more updated curricula and following a Western style and the fact they offer courses which are of some link to Kurdish politics and society, have not totally halted this gap to exist.

Nonetheless, the picture is not entirely bleak. There is a strong recognition by professors, especially younger generation, that sociology in Kurdistan has to shift the direction and that Kurdish sociologists need to struggle to establish their own sociology. Our findings show that sociology professors are able to identify shortcoming in the content of what they teach and the way they deliver them. There has been emphasis on the need to develop theories about Kurdish society and make them subjects of sociology education in Kurdistan. However, from a policy perspective, intervention is needed in order to empower younger professors who are institutionally not powerful to shape academic policies of their departments.

In addition to department-based differences, there are obvious individual-based differences among professors. This partly, and importantly, reflects the differences in the trainings and experience of professors. Put it in other words, in the three departments covered in this project, in each department different 
viewpoints raised with respect to sociology and different levels of satisfaction were reported with sociology education in their own departments.

Another area of alienation is manifested in widely shared disappointment of sociology professors and students alike in the contribution of sociology in social change and development. The awareness with respect to the significance of sociology and the ways in which it can serve change is confronted by authorities neglect and society's lack of conception about sociology. In some cases, sociology professors and students alike find themselves in clash with dominant culture and religious authorities.

Sociology professors have been successful in carrying out research projects on social problems of Kurdish society. There have been publications about social problems, social phenomenon, women and gender, crime and deviance, technology and social problems, politics, genocide and so on. Nevertheless, there are challenges with circulation of research projects, linking research projects to teaching and methodological simplicity of the projects. With respect to circulation of projects, apparently professors tend to be unaware of other Kurdish sociologists' publications. Apart from the fact that up until very recently most of Kurdish academic journals was not accessible online, seemingly the Kurdish sociological community lack interaction opportunities. In many instances professors complained that they cannot meet other sociologists in meetings, conferences and other academic forums. Related to that is disconnection of research from teaching. For some professors, their research projects have been far away from courses they teach. Almost none of professors interviewed mentioned if they use their research projects or their colleagues' publications in their course reading lists. Additionally, overwhelming majority of research projects are quantitative/survey based projects. The new generation of sociologists, especially those received training in Western countries, have made efforts, albeit with difficulty, to diversify research methodologies.

Students' conception of sociology prominently echoes professors' conception of the field. Whereas students at University of Salahaddin Hewler and University of Sulaimani conceptualize sociology in non-critical way, at Soran University a more radical and critical conception of sociology prevails. Sociology, in the latter case, is tasked with challenging oppressive cultures and discriminatory structures. With respect to course preferences, students show interest in courses for which course professors have successfully linked their teaching with the reality of Kurdish society, i.e. less alienated courses and where they built a more egalitarian relationship with students.

Taking all these into consideration, this research shows clearly that valiant efforts are needed to enable the Kurdish sociologists to have their own sociology. Sociology departments are also supposed to ensure that sociology education reflects the Kurdish society. Organizing regular meetings, workshops, and conferences to discuss sociological methods, researches, curricula, and critical pedagogy is also valuable not only to develop the discipline itself, but also to streng- 
then professional bonds between the Kurdish sociologists. Additionally, online platforms can be significant tools to make sociological researches and publications of Kurdish sociologists accessible in the community of social sciences.

\section{Conflicts of Interest}

The authors declare no conflicts of interest regarding the publication of this paper.

\section{References}

Abdul-Hussain, L. (2014). The Future of Sociology in Iraq: Challenges and Prospects. Idafat Journal, 25, 9-27. (In Arabic)

Al Hashimi, H. G. (2013). Iraqi Sociology and Al Wardi's Contributions. Contemporary Arab Affairs, 6, 251-259. https://doi.org/10.1080/17550912.2013.784545

American Sociological Association (2018). Teaching Sociology Journal. https://uk.sagepub.com/en-gb/mst/journal/teaching-sociology\#description

Atrushi, D. S., \& Woodfield, S. (2018). The Quality of Higher Education in the Kurdistan Region of Iraq. British Journal of Middle Eastern Studies, 45, 644-659. https://doi.org/10.1080/13530194.2018.1430537

Bagader, A. (1997). The State of Arab Sociology as Seen by an Arab Sociologist. In Questions from Arab Societies (pp. 62-72).

Braa, D., \& Callero, P. (2006). Critical Pedagogy and Classroom Praxis. Teaching Sociology, 34, 357-369. https://doi.org/10.1177/0092055X0603400403

Fobes, C., \& Kaufman, P. (2008). Critical Pedagogy in the Sociology Classroom: Challenges and Concerns. Teaching Sociology, 36, 26-33. https://doi.org/10.1177/0092055X0803600104

Freire, P. (1970). Pedagogy of the Oppressed (Ramos, M.B., Trans.). New York: Continuum, 2007.

Halasz, J. R., \& Kaufman, P. (2008). Sociology as Pedagogy: How Ideas from the Discipline Can Inform Teaching and Learning. Teaching Sociology, 36, 301-317. https://doi.org/10.1177/0092055X0803600401

Kaufman, P. (2002). Critical Pedagogy in the Sociology Classroom. Washington DC: American Sociological Association.

Hakim, M. (2011). The State of Values in Iraq. PhD, Hewler: University of Salahaddin.

Hakim, M., \& Muhammad, A. (2017). Positivism and Sociology in the Kurdistan Region. Humanities Journal of University of Zakho, 5, 959-972. (In Kurdish)

Hakim, M. (2017). Drawing Sampling in Sociology; a Critical Perspective toward Drawing Sampling by Sociologists in the Kurdistan Region. The Journal of Humanities and Social Sciences of Koya University, No. 44, 255-300.

Ibrahim, S. E. (1997). Cross-Eyed Sociology in Egypt and the Arab World. Contemporary Sociology, 26, 547-551. https://doi.org/10.2307/2655614

Qazzaz, A. (1980). General Impressions on Sociology in Iraq between 1950-1970s. Journal of Al-Khalij wa Al-Jazzera, 4, 55-62.

Rasul, I. (2018). Bibliography of Sociological Researches. Erbil: Kurdistan Sociological \& Psychological Association (Kurdish).

Tayefi, A. (2010). Challenges of Sociology in Iran (Ups and Downs and Perspective of Exit). Asian Social Science, 7, 170. https://doi.org/10.5539/ass.v7n1p170 